\title{
1. Organizations and global environmental change
}

Not all organizations adapt equally well to the environment within which they grow.

Many, like the dinosaur of great size but little brain, remain unchanged in a changing world.

Charles Handy

\section{INTRODUCTION}

Since the beginning of the Industrial Revolution in the middle of the eighteenth century, global concentrations of greenhouse gases (GHGs) such as carbon dioxide $\left(\mathrm{CO}_{2}\right)$, methane $\left(\mathrm{CH}_{4}\right)$, and nitrous oxide $\left(\mathrm{N}_{2} \mathrm{O}\right)$ have risen significantly and have substantially contributed to the warming of the Earth's atmosphere through the so-called greenhouse effect. The increase in $\mathrm{CO}_{2}$ concentrations can primarily be attributed to the burning of fossil fuels such as coal, natural gas, and oil, as well as land-use changes such as deforestation. Increases in methane and nitrous oxide have primarily been linked to agriculture expansion and intensification (CSIRO, 2009). Examples include methane emissions from livestock and rice cultivation, or emissions of nitrous oxide from fertilized soils (Foley et al., 2011). Even though the extent to which climate change will impact society is still debated, it is clear that the role of business activity is a key matter in the debate about climate change. Businesses have been central to the creation of the wealth and technologies that have transformed society (Michaelis, 2003), but, at the same time, economic growth has also been a major driver behind the intensification of natural resource use and consumption to unsustainable levels.

Overall, there are very few aspects of current society that are not organized into or impacted upon by corporate activities. Consolidating and systemizing human production efforts into organizations has allowed for the accomplishment of economic activities beyond the means of individuals. This was achieved through the division of labor into various tasks to be performed and the introduction of organizational structures to 
allow for a coordination of these tasks (Mintzberg, 1983). Organizations have taken important roles in society in providing services, ranging from the provision of energy to transportation, food and health services. However, the industrialization and the arrival of the modern corporation at the turn of the twentieth century have led to concerns about the impacts of rational, utility- and profit-maximizing behaviors on society and the environment. It soon became clear that the growing levels of economic growth and industrialization and the primary pursuit of shareholder interests led to the exploitation of finite flows of natural resources, rather than their long-term conservation for the benefit of all (Nordhaus and Radetzki, 1994; Ostrom, 1999). The limits of exponential growth models and their impacts on natural systems became visible as they did not take into consideration the limitations of natural systems.

The available scientific evidence makes it clear that economic growth is not just interfering with the Earth's climate system. The scale of human activity, together with population growth and growing levels of resource consumption, has resulted in important changes to the Earth's systems. In addition to changes within the Earth's climate system, these include: accelerated biodiversity loss, interference with the nitrogen and phosphorus cycles, stratospheric ozone depletion, ocean acidification, depletion of global freshwater resources, adverse changes in land use, rising levels of chemical pollution, and atmospheric aerosol loading (Bateman et al., 2011; Rockström et al., 2009b). Studies assessing the state of the environment report that many ecosystems are in an alarming state of decline, and a further significant degradation is projected (Millennium Ecosystem Assessment, 2005b). The United Nations HighLevel Panel on Global Sustainability concluded that 'The current global development model is unsustainable. We can no longer assume that our collective actions will not trigger tipping points as environmental thresholds are breached, risking irreversible damage to both ecosystems and human communities' (United Nations, 2012: 4).

Indeed, the scale of human and industrial activities is now seen as severe enough to potentially bring about large-scale, adverse global change. The US Global Change Research Act 1990 defines 'global change' as 'changes in the global environment (including alterations in climate, land productivity, oceans or other water resources, as well as atmospheric chemistry and ecological systems) that may alter the capacity of the Earth to sustain life'. This definition is directly expressing concerns about the large-scale degradation of the Earth's carrying capacity and the far-reaching impact of modern economic activities on the biosphere, natural resource depletion and ecosystem functioning. 
Despite the large number of environmental problems caused by human activity, climate change has emerged as one of the most pressing issues, in particular due to concerns about changes in weather and climate patterns, as well as concerns about a greater occurrence of weather extremes and resulting disasters. It is estimated that humanity has by now transgressed the boundary level of $\mathrm{CO}_{2}$ emissions that should not be transgressed if we are to avoid unacceptable global environmental change (Rockström et al., 2009a). Many impacts of climate change are already observable. Furthermore, climate change is an important driver and accelerator of vulnerabilities in other systems, such as agricultural systems and freshwater resources (IPCC, 2007a, 2013).

The global reach of corporations and the role of business activities in bringing about large-scale environmental change have triggered political and societal discussions about the implementation of more sustainable business practices. However, despite a growing number of initiatives (some with considerable success at lowering resources and energy consumption), environmental degradation and GHG emissions levels are overall on the rise. Researchers have noted the paradox surrounding corporate sustainability. On the one hand, actions such as the implementation of energy-saving measures have been among the most popular topics within the business community. Recent years have also seen a significant uptake of environmental reporting under the mantra of: 'what gets measured gets acted upon' (Confino, 2013). Sustainability is therefore no longer a fringe topic and organizations have started to act on ecological issues. On the other hand, collective action on climate change is not strong enough to prevent global emissions from rising, and to avoid an overall worsening of the state of the environment (Whiteman et al., 2013). Some contributions aside, action on climate change is a topic that has commanded little interest in business practice, management journals and business schools.

Looking at GHG emissions data, some of the world's largest companies are now emitting more GHGs than entire nations. The emissions of large, resource-intensive corporations such as Exxon Mobil are larger than those of smaller European states such as Belgium (see Figure 1.1), not measuring other negative externalities such as environmental pollution and ecosystem degradation. The extent of an individual corporation's contribution to climate change and other types of adverse global changes is still a topic absent from many boardrooms - in some cases because the impacts of corporate activities on the environment have not been fully assessed, in other cases because climate change is not perceived as an issue that requires immediate management attention beyond compliance with regulatory requirements. This is not to say that individual corporate 


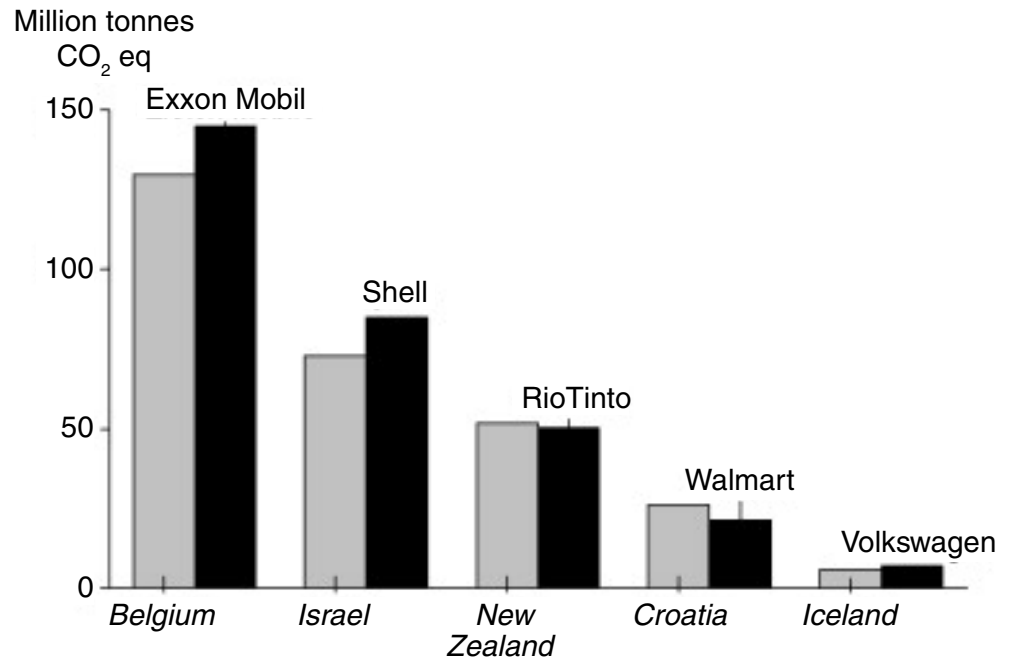

Source: Patenaude (2011). Reprinted from Global Environmental Change, Vol. 21, Iss. 1, Patenaude, G. (2011), 'Climate change diffusion: While the world tips, business schools lag', pp. 259-71. Copyright (2011) with permission from Elsevier.

\section{Figure 1.1 Carbon emissions by companies}

actions have been unsuccessful in addressing sustainability or mitigating emissions; rather, progress on an aggregate level is slow at best. In addition, little is known about the extent to which attempts at integrating sustainability into corporate decision-making actually contribute to ecologically beneficial outcomes (Kallio and Nordberg, 2006). The potential issue is that by making an organization more efficient, we also provide this organization with the capacity to use more resources in an efficient and unsustainable way.

The lack of stringent reductions in global GHG emissions and the resulting greater potential for adverse consequences of climate change has resulted in researchers putting forward stronger arguments for creating adaptation and resilience to climate change impacts in addition to a focus on mitigation (Dow et al., 2013). At the 2013 First European Climate Change Adaptation Conference in Hamburg, Germany, Nigel Arnell (Director of the Walker Institute for Climate Change Research and Professor of Climate System Science in the Department of Meteorology at the University of Reading) concluded in his address to the conference that mitigation might reduce some, but does not eliminate the impacts of climate change. Overall, given that the consequences of climate change 
can increasingly not be avoided as climate change progresses, a strong imperative for adaptation and resilience strategies to address projected climate impacts and related changes in ecosystems thus emerges. The feasibility of any action will thereby largely depend on the future state of society and the economy (Arnell, 2013).

\section{A Brief History of Organizations and the Environment}

While many decision-makers are aware of the topic of sustainability and have started to consider changes to their organizations' production processes and service delivery to lower their resource inputs and throughputs, organizational behavior is largely occurring in a way that is decoupled from a changing environment. The most frequently cited reasons for a lack of more stringent business action on climate change are short-termism and profit-orientation. This leads to a tendency of organizational decision-makers to rarely consider the long-term implications of organizational actions on the environment as well as the long-term impacts of a changed natural environment on their organizations' operations (Winn et al., 2011). However, the possibility that unsustainable levels of resource consumption can result in adverse environmental changes with significant negative outcomes for society (not only on a local but also on a global scale) is fully recognized and was already extensively documented by the nineteenth century (Malthus, 1878; Marsh, 1864; Mill, 1848). ${ }^{1}$

The warming effect of gases in the atmosphere was first discovered by the French mathematician Jean-Baptiste Fourier in 1827. Fourier pointed to the similarities between the earth's atmosphere and the glass of a greenhouse, which later led to the term 'greenhouse effect'. Further early research was undertaken in 1860 by John Tyndall who measured the absorption of infrared radiation by water vapor and $\mathrm{CO}_{2}$, as well as by Svante Arrhenius in 1896 who calculated the effects of an increasing concentration of GHGs in the atmosphere (Houghton, 2004). From the beginning of the industrial revolution onwards, it became increasingly evident that the activities of modern corporations were becoming a major contributor to environmental problems and increasing levels of GHGs in

1 Knowledge about the environmental impacts caused by human activity dates back much further, including traditional knowledge about how deforestation, and inappropriate resource use such as water or soil depletion led to the decline and collapse of ancient civilizations. See Weiskel, T.C. (1989), 'The ecological lessons of the past: an anthropology of environmental decline', The Ecologist, 19(3): 98-103. 
the atmosphere. Environmental problems and concentrations of GHGs were intensifying with the aggregate level of activities and resource exploration.

Despite these initial studies, research on global warming came to a halt until the 1950s when scientists realized that several regions of the world had warmed significantly during the previous half-century. The first expression of concern about increasing levels of GHG emissions and their contribution to climate change was made by Revelle and Suess (1957) who published a paper on the build-up of $\mathrm{CO}_{2}$ in the atmosphere. In the same year, regular measurements of the level of $\mathrm{CO}_{2}$ in the atmosphere were started in the US from the observatory of Mauna Kea in Hawaii (Houghton, 2004).

A systematic identification of the role of industries and organizations in driving environmental change did not begin until the 1960s and 1970s, with an initial focus on environmental pollution and degradation brought about by corporate activities. At the time, highly visible ecological problems and growing awareness about the state of the environment galvanized public attention to oppose the negative health and environmental effects caused by organizations, and created a wave of support for stricter government regulations (Fischer and Schot, 1993; Hart, 1995, 1997). The book Silent Spring by Rachel Carson (1962) has been cited by many as a turning point in raising societal awareness about the severity of environmental degradation, and became a catalyst for the environmental movement of the 1960s and 1970s. In her book, Carson presented findings that agricultural pesticides (in particular DDT) were building up to dangerous levels and causing damage to both animal species and to human health. While the industry journal Chemical Week initially denounced Carson's findings, more and more evidence emerged which underpinned her claims and pointed to serious environmental problems brought about by industrial activities. These included the dispersion of toxic chemicals and waste (Maugh, 1979), the extinction of species (Bishop, 1978), acid rain (Likens and Bormann, 1974) and issues such as widespread air pollution, water pollution and soil contamination (Nriagu and Pacyna, 1988). The US Science Advisory Committee, tasked by John F. Kennedy to review the claims presented in Silent Spring, largely confirmed Carson's conclusions.

The media coverage following Silent Spring, along with a number of high-profile environmental disasters (for example, mass deaths of fish, major oil spills such as the Amoco Cadiz oil spill, the Love Canal scandal in the US, as well as mercury and cadmium poisoning in Japan) fueled a public outcry over environmental pollution and degradation caused by organizations. The First Earth Day was held in the US, not 
only capitalizing on the emerging environmental consciousness, but also on the growing awareness of social issues and the anti-war protest movement in the country. Although the environmental movement paid attention to the cumulative effects of individuals' consumption practices along with rapid population growth and economic development, especially in developing regions (Ehrlich, 1968), organizations were generally identified as the major culprits for environmental problems as a result of their bigger reach, greater resource access, and greater economic interests compared to individuals (Hart, 1997). Yet, despite growing public pressure and new government regulations during the 1970s and early 1980s, organizations did in most cases little more than to comply with legal requirements, and often attempted to fight or hinder them (Walley and Whitehead, 1994). Organizations needed to establish and finance environmental compliance functions alongside existing compliance functions such as health and safety, thus increasing their costs.

The extent of environmental degradation was eventually recognized on an intergovernmental level and led to the 1972 United Nations Conference on the Human Environment (UNCHE) in Stockholm, Sweden. The UNCHE was a first attempt to quantify the global human impact on the environment and to define principles for addressing the challenge of environmental preservation. Following this conference, the United Nations Environmental Programme (UNEP) was established. At the same time, the publication of Limits of Growth by the Club of Rome (Meadows et al., 1972) sparked a debate around the compatibility of economic and population growth with environmental protection. The 'growth versus environment' debate that followed questioned the validity of growth as a goal of society in general, assuming that indefinite future growth is impossible (Kidd, 1992). In order to prevent further environmental destruction, some economists proposed a shift towards a 'steady state economy' with no further growth (Daly, 1973, 1974) or even a reduction in both economic activity and population levels (Grant, 2000). Such propositions were viewed by many as too radical, thus shifting the discussion away from a 'growth versus environment' debate (Pearce et al., 1989) towards notions that some form of sustainable development is possible. The 1987 report Our Common Future by the World Commission on Environment and Development (WCED), for instance, popularized the notion of 'sustainable development', defined as: 'development which meets the needs of the present without compromising the ability of future generations to meet their own needs' (WCED, 1987).

During the mid- to late-1980s, and among further environmental disasters (for example, the Exxon Valdez oil spill, the Chernobyl nuclear disaster and the Bhopal gas disaster), several leading organizations began 
to change their position from ignoring or resisting environmental pressures to attempts to profit from them (Fischer and Schot, 1993; Starik and Marcus, 2000). Their responses were referred to as "market-driven environmentalism' (Post and Altman, 1994: 65) and led to a widespread introduction of environmental management systems (for example, ISO14001) along with written policy statements, larger environmental departments and more extensive external contacts with a range of stakeholders including environmental groups (Fischer and Schot, 1993; Starik and Marcus, 2000). Organizations were able to achieve easy, but often very significant improvements and cost-savings, mainly through the introduction of pollution prevention and waste minimization initiatives (Post and Altman, 1994; Walley and Whitehead, 1994). Consequently, environmental considerations also started to play a greater role in capital investment decision-making and in new product development (Starik and Marcus, 2000).

Organizations attempted to capitalize further on the cost and competitive opportunities of engaging with environmental issues. Many organizations started to analyze the impact of their engagement with environmental issues on their corporate profitability and competitive advantage, for instance through environmental impact or life cycle assessments. Some organizations sought to develop internal capabilities to achieve a sustainable competitive advantage, including measures aimed at preventing pollution and improving the efficiencies of resource use (so-called eco-efficiencies) (Hart, 1995, 1997; Lovins et al., 1999). During this time, organizations also faced increasing pressures to disclose environmental information, which gave rise to environmental performance reporting. A wide variety of terms have been used to describe this development, including corporate 'greening' (Gladwin, 1993) and 'corporate environmentalism' (Hoffman, 2001; Jones and Levy, 2007). However, eco-initiatives and efficiency improvements did not automatically translate into total environmental performance improvements that can be attributed to overall consumption growth (Schot et al., 1997; Starik, 1995). The pursuit of sustainability was driven by the primacy of economic considerations over environmental concern for many, if not most corporations.

The late 1980s and early 1990s saw the emergence of a different type of environmental concern beyond environmental protection per se. The environmental movement of the 1960s and 1970s was driven by media attention and stakeholder pressures in response to highly visible, yet local and often reversible forms of pollution and environmental degradation. However, the discovery of the 'ozone hole' and the realization that climate change was posing a longer-term, irreversible, and global threat, 
were primarily driven by scientific research. Research findings started to point to environmental problems at a much larger scale (Bodansky, 2001). In 1988, the World Meteorological Organization (WMO) and the UNEP established the Intergovernmental Panel on Climate Change (IPCC) in an attempt to bring together international climate experts to synthesize the most recent climate science findings, and assess the state of scientific knowledge on climate change. These developments (summarized in Table 1.1) culminated in the 1992 United Nations Conference on Environment and Development (UNCED) in Rio de Janeiro and the United Nations Framework Convention on Climate Change (UNFCCC) which had great impact on the international policy agenda (CantleySmith, 2010), and resulted in the adoption of climate policies on a national level (as outlined in Chapter 4).

Increasing concerns about declining environmental quality, increasing population growth, rising living standards, and the increasing rates of consumption of resources (for example, of energy, natural resources and food) also led to an increasing level of environmental legislation. During the 1960s and 1970s several environmental laws were passed that introduced water and air quality standards in highly industrialized countries, including the US and countries across Europe (for example, the Clean Air Act 1963, the Clean Air Act 1970, the Water Quality Act 1965, the Air Quality Act 1967, the Safe Drinking Water Act 1974, and the National Environmental Policy 1969 in the US). This also led to the formation of corresponding institutions such as the US Environmental Protection Agency (US EPA). Increasingly, regulations were introduced relating to consumer and environmental protection (for example, the US Consumer Product Safety Act 1972) as well as the management of hazardous materials (for example, the US Toxic Substances Control Act 1976). In addition, greater attention was paid to waste management, resource efficiencies and the regulation of agricultural and industrial practices.

At around the same time, the notion was advanced that businesses can and should help society in achieving the three goals of environmental protection, social equity and economic prosperity (Elkington, 1997). The World Business Council on Sustainable Development (WBCSD) coined the term 'eco-efficiency' in the 1992 publication Changing Course to refer to what the WBCSD saw as a new management philosophy to encourage businesses to implement environmental improvements that result in parallel economic benefits (Schmidheiny, 1992). However, the wide acceptance of achieving 'eco-efficiencies' as the key strategic theme for businesses in relation to achieving sustainable commitments and activities has not been without criticism. For one, issues concerning 


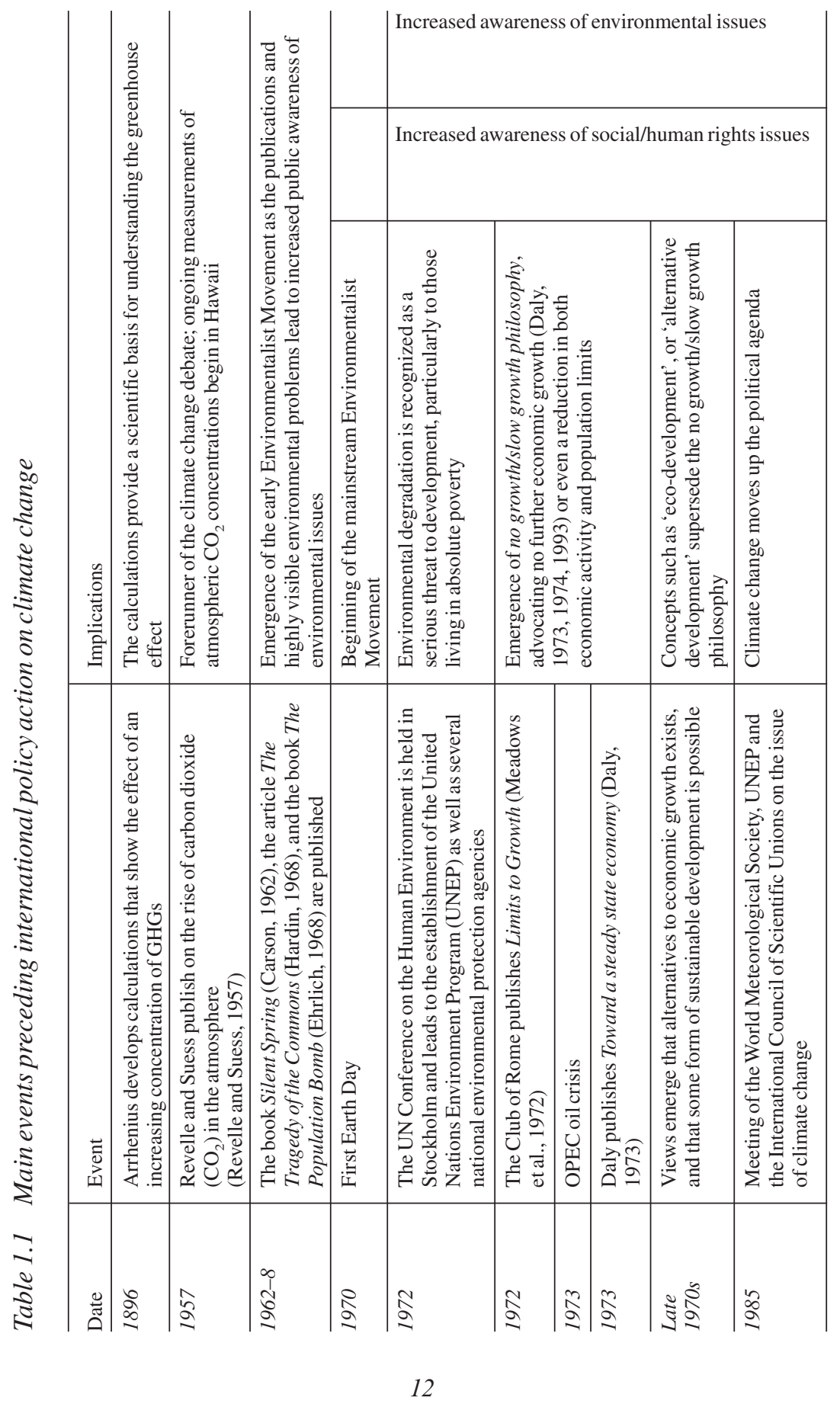




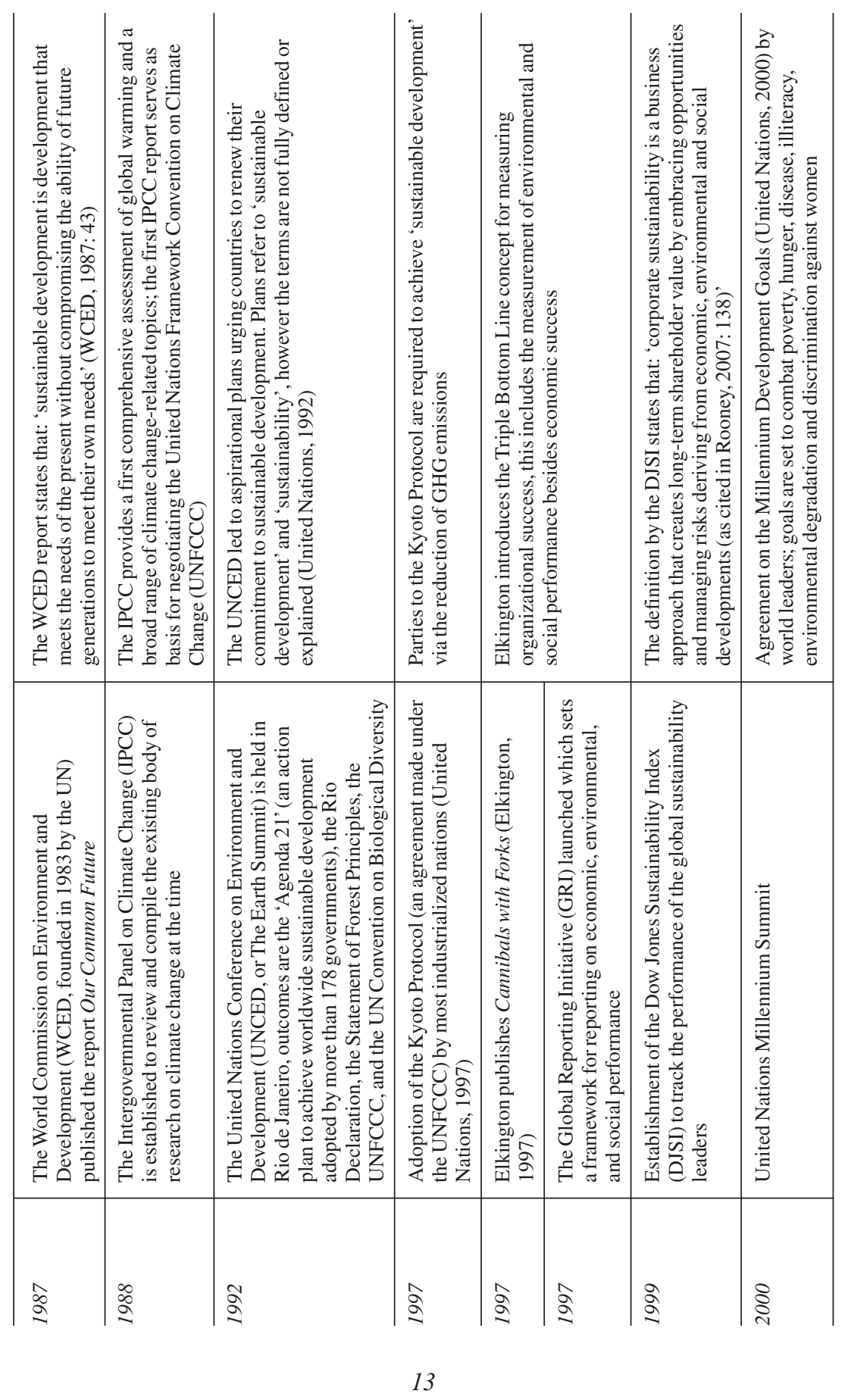




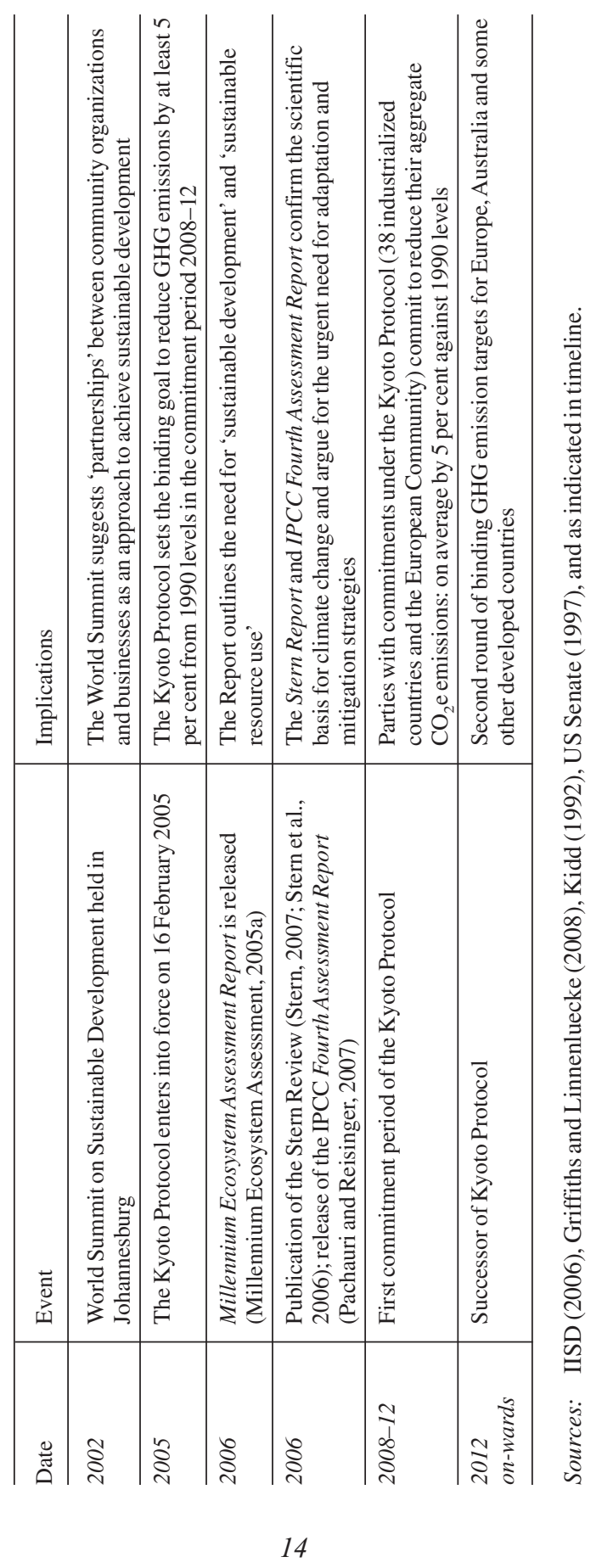


equity and other social properties are not included in the concept. In addition, computing 'environment improvements' in relation to economic benefit faces additional issues: what type of improvements should be included in any calculation, what boundaries are appropriate, and what metrics should be used (Ehrenfeld, 2005)?

The pursuit of eco-efficiencies has also been criticized for not leading to any significant radical changes in business models, away from unsustainable models of production and consumption. For instance, rather than 'revolutionizing' their business models, many companies responded to the slowly emerging climate policy landscape by making operational improvements and eliminating inefficiencies in energy- or fuel-intensive processes that stem from poor planning and the inefficient use of natural resources. In many cases such strategies allowed companies to reduce carbon emissions while also exploiting benefits associated with lower resources use (Hart, 1995, 1997). Well laid-out energy or resource efficiency programs have certainly significant benefits not only for reducing emissions, but also for improving financial performance and competitive advantage in the short term if cost-savings were being realized (Sharma and Aragón-Correa, 2005). However, it needs to be questioned whether established patterns of organizational responses with a focus on complying with regulation and seeking to exploit efficiencies are suited to respond to a vastly changed external environment in a new era of environmental change.

Organizations that only pursue efficiency gains and emission reduction strategies may neglect building adaptive capacity to the physical impacts that climate change will have on their operations (along with social, political and economic impacts that will emerge in the longer term). Indeed, many managers have not yet systematically considered the industry-level and organizational-level implications of a more volatile natural environment, such as changes in the intensity and frequency of storms, floods, and droughts. While some organizations (for example, agricultural companies) have traditionally been more exposed to weather extremes and have built adaptive responses, most current debates on climate change and corporate responses are limited to reducing GHG emissions. Exceptions can be found in sectors that are strategically affected by climate change and have begun to investigate the impacts of future trends of weather extremes on their business (for example, reinsurance firms such as Munich Re and Swiss Re). 


\section{Is There a Tipping Point?}

Society may be lulled into a false sense of security by presuming that adaptation is possible due to the often smooth and gradual projections of climate change, and that that climate change thus does not pose any real threat (Lenton and Schellnhuber, 2007). Indeed, larger-scale changes beyond gradual temperature rise are often not considered in the public debate, or are seen as highly unlikely. However, scientists have put forward evidence concerning the existence of so-called tipping points in relation to climate change and resulting impacts (Kriegler et al., 2009; Nepstad et el., 2008). A tipping point can be defined as a threshold beyond which a system moves into a qualitatively different state, usually brought about by a small level of additional change or pressure (Lenton et al., 2008). An example can be a light switch - if only a small amount of pressure is applied, the light will not turn on. However, beyond a certain amount of pressure, the light switch will flick into a different state - and turn the light on (Gunderson and Holling, 2002). Exceeding a tipping point might lead to what is referred to as 'dangerous' climate change. The 1992 UNFCCC text (see Chapter 3) states that:

[t]he ultimate objective of this Convention and any related legal instruments that the Conference of the Parties may adopt is to achieve, in accordance with the relevant provisions of the Convention, stabilization of greenhouse gas concentrations in the atmosphere at a level that would prevent dangerous anthropogenic interference with the climate system. Such a level should be achieved within a time frame sufficient to allow ecosystems to adapt naturally to climate change, to ensure that food production is not threatened and to enable economic development to proceed in a sustainable manner. ${ }^{2}$

The objective 'to achieve [...] stabilization of greenhouse gas concentrations in the atmosphere at a level that would prevent dangerous anthropogenic interference with the climate system' has been criticized as being too vague, as the meaning of 'dangerous anthropogenic interference' can be interpreted in many different ways. This statement does not specify a level of global warming that is dangerous (New et al., 2011), nor does it provide any specific timeframe and/or targets for actions. While this is problematic for the implementation of any GHG reduction targets, it is not surprising that the statement by the UNFCCC has not been more specific regarding what constitutes 'dangerous' levels of climate change. The existence of tipping points in relation to climate change (and the

2 The full text of the Convention is available, accessed 20 October 2014 at http://unfccc.int/resource/docs/convkp/conveng.pdf. 
quantification of accumulated change needed to reach a tipping point) is still surrounded by uncertainty. Nonetheless, there is ample evidence on a smaller scale that human activities can push components of the Earth's systems (for example, ecosystems) past a critical threshold into qualitatively different modes, leading to the assumption that such changes can also occur on a planetary scale (Lenton et al., 2008). Examples of possible consequences of threshold exceedance include the potential collapse of the Atlantic thermohaline circulation (THC), dieback of the Amazon rainforest, and the collapse/decay of major ice sheets (Kriegler et al., 2009; Nepstad et al., 2008).

A commonly cited threshold or 'guard rail' for 'safe' levels of temperature rise is the so-called $2^{\circ} \mathrm{C}$ target as the upper limit of warming permissible to avoid dangerous anthropogenic interference in the climate (Randalls, 2010). The assumption is that a global mean temperature increase of up to $2^{\circ} \mathrm{C}$ relative to pre-industrial levels is likely to allow many human systems to adapt to climate change at globally acceptable economic, social and environmental costs (EG Science, 2008). The target has been advocated by the European Union as well as in the 2009 Copenhagen Accord that states: 'the increase in global temperature should be below 2 degrees Celsius'. However, the $2^{\circ} \mathrm{C}$ target dates back to the 1970s when scientists and economists sought to develop heuristics for policy decision-making on climate change (Randalls, 2010) - while the GHG emissions corresponding to a specified maximum warming are in fact poorly known (Meinshausen et al., 2009).

There are growing views that this threshold estimate might be too high (New et al., 2011) and not represent a reliable threshold. A $2^{\circ} \mathrm{C}$ target is committing the world to a significant degree of climate change, without much knowledge regarding whether or not it really prevents dangerous levels of climate change. Many negative effects of climate change are already observable under the current levels of global temperature increase (about $0.6^{\circ} \mathrm{C}$ to $0.7^{\circ}$ over the period $1951-2010$ ), and the adaptive capacity of many ecosystems might be well be exceeded before a $2^{\circ} \mathrm{C}$ increase is reached (EG Science, 2008). Attempts at estimating a GHG emission target for limiting global warming to $2^{\circ} \mathrm{C}$ suggest that limiting cumulative $\mathrm{CO}_{2}$ emissions over the period from 2000-2050 to $1,000 \mathrm{GtCO}_{2}$ (gigatons of $\mathrm{CO}_{2}$ ) would yield a 25 per cent probability of global warming exceeding $2^{\circ} \mathrm{C}$. Limiting cumulative $\mathrm{CO}_{2}$ emissions to $1,440 \mathrm{GtCO}_{2}$ over the same period would yield a 50 per cent probability of global warming exceeding $2^{\circ} \mathrm{C}$ (Meinshausen et al., 2009). This budget could easily be exhausted by 2027 or 2039 respectively (Meinshausen et al., 2009). However, the continued rise in GHGs along with a 
lack of a stringent and comprehensive global emission reduction agreement have made achieving a $2^{\circ} \mathrm{C}$ target extremely difficult (if not impossible) - which raises the likelihood of global temperature rises of $3^{\circ} \mathrm{C}$ or $4^{\circ} \mathrm{C}$ within this century (New et al., 2011). In our view, such a range would require significant and timely adaptive measures.

\section{The Existence of Planetary Boundaries}

Given the shortcomings of the $2^{\circ} \mathrm{C}$ target, new approaches emerged for estimating how dangerous levels of climate change and other types of global changes can be avoided. One such approach is the concept of 'planetary boundaries' (Rockström et al., 2009a; Rockström et al., 2009b). Rather than focusing on thresholds, the authors propose boundaries for human-induced pressures on the Earth's systems. Boundaries, in contrast to thresholds, are values of a variable (for example, temperature increases) set at a 'safe' distance from a dangerous level that should not be transgressed if unacceptable levels of global change are to be avoided. Determining this safe distance involves normative judgments of how much risk and uncertainty society is prepared to deal with. The authors identified nine planetary boundaries and offer quantifications for seven based on current scientific evidence. These seven boundaries are: climate change, ocean acidification, stratospheric ozone concentration, the biogeochemical nitrogen $(\mathrm{N})$ and phosphorus $(\mathrm{P})$ cycles, global freshwater use, land-use system change, and the rate at which biological diversity is lost. The proposition is that $\mathrm{CO}_{2}$ concentration in the atmosphere should be lower than $350 \mathrm{ppm}$, and/or that the maximum change in radiative forcing ${ }^{3}$ should be $+1 \mathrm{~W} / \mathrm{m}^{2}$ (watts per square meter) - estimated by Hansen and Sato (2012) to result in a temperature change of approximately $0.75^{\circ} \mathrm{C}$.

Looking at the existing evidence and the extent of already observable climate change, it is evident that the climate change boundary has already been transgressed. In addition to climate change, it is estimated that humanity has also transgressed boundaries for the rate of biodiversity loss and the rate of interference with the nitrogen cycle (driven by

3 The IPCC (2007: 36) defines radiative forcing as follows: 'Radiative forcing is a measure of the influence a factor [e.g., the atmospheric concentrations of GHGs and aerosols, land cover, solar radiation] has in altering the balance of incoming and outgoing energy in the Earth-atmosphere system and is an index of the importance of the factor as a potential climate change mechanism. [...] radiative forcing values are for changes relative to preindustrial conditions defined at 1,750 and are expressed in Watts per square meter $\left(\mathrm{W} / \mathrm{m}^{2}\right)$.' 
agricultural activities and fertilizer use). Knowledge gaps and uncertainties exist in regards to the duration over which boundaries can be transgressed before causing unacceptable environmental change and the ability to return to a safe level once a dangerous level is reached (Rockström et al., 2009a; Rockström et al., 2009b). At the same time, however, approaching or transgressing any of the boundaries should not be seen as a fatalist excuse for inaction. First, decisive actions can reverse negative trends, as demonstrated with regard to the stratospheric ozone boundary. The signing of the Montreal Protocol (along with subsequent amendments) led to a reversal of a trend towards stratospheric ozone depletion (Rockström et al., 2009a). Decisive action on climate change could bring about similar successes. Second, interdependencies between boundaries need to be taken into consideration, suggesting that simultaneous actions should be undertaken. Third, the consequences of transgressing a boundary need to be evaluated, such that adaptive action can be undertaken to minimize impacts.

\section{Scales of Change}

Environmental problems are no longer localized. Scientific evidence increasingly points to global systematic changes in the environment (including climate change) that are linked to and regulated by a complex set of local processes (for example, local processes driving GHG emissions and land-use changes). At the same time, global changes have local and regional impacts and manifestations. The increasing extent of environmental problems beyond localized boundaries makes a consideration of both spatial and temporal scales important. 'Scale' in this context can be defined as a spatial, temporal, quantitative, or analytical dimension important for assessing problems and finding solutions (Cash et al., 2006; Gibson et al., 2000). A level within a scale refers to a unit of analysis located on a scale (often in a hierarchical manner). For instance, levels within a spatial scale could refer to patches, landscapes or regions up to the global level (Cash et al., 2006; Gibson et al., 2000).

The concept of scale is crucial for understanding interactions of organizations, industry and society with the natural environment. The first and most important concern is the increasingly global scale of adverse environmental consequences brought about by aggregate individual-level, organizational-level and industry-level activities. To date, however, the issue of scale in understanding the relation between organizations and the environment has been ignored or simplified (here defined in a broad sense to encompass both economic and environmental variables) (Gibson et al., 2000). Decision-makers within organizations 

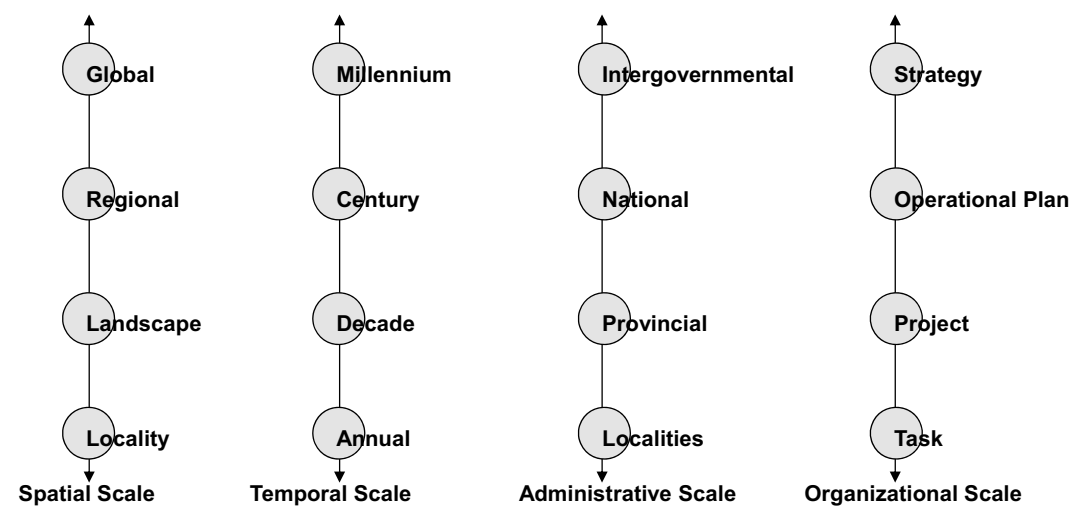

Source: Adapted from Cash et al., 2008.

\section{Figure 1.2 Scales of change}

tend to focus on relatively fast-moving variables on organizational and industrial levels (for example, financial resources, innovation capabilities, cost considerations, financial outcomes, or competitor moves), while the dynamics of a changing natural environment have typically not been considered in organizational decision-making. Business activities are often occurring in a way that is disconnected from the natural environment, not fully recognizing the importance of the natural environment, particularly its role in providing organizations with natural resources as operational inputs, a sink for waste, and stable, predictable natural environmental conditions (to the sectors that depend on this) (Linnenluecke and Griffiths, 2011). This book explores issues across a number of different scales and levels.

Administrative scales Jurisdictional or administrative scales range from local administrative units (for example, local councils) to provinces or states, national governments and even intergovernmental levels. They are often closely related to spatial scales (see below) as they introduce a system of rules for certain geographic areas. In addition, jurisdictional or administrative scales often also introduce a system of rules between different levels, thus determining how rules or legislation are applied, introduced and amended over time (Cash et al., 2006). In the context of organizational responses to climate change, the importance of jurisdictional and administrative scales becomes evident when looking at institutional arrangements on state, regional and local level that introduce legislative or compliance requirements. Administrative requirements, 
especially if mandatory and enforced, are drivers governing organizational and industry responses to environmental issues (see also Chapters 3 and 4). In addition to mandatory requirements, some jurisdictions have voluntary programs targeting specific organizations or industries.

Beyond jurisdictional and administrative scales, businesses and other organizations have not been paying much attention to the issue of scale in decision-making, and especially in their response to climate change. For instance, organizations are typically not concerned with issues beyond their planning horizons. Organizations have also not been paying much attention to the relevance of geographic scale for economic activity beyond the importance of location for organizational growth over time. For example, few organizations have considered how the scale of economic activity relates to ecosystem dynamics (Brouwer, 2010; Linnenluecke and Griffiths, 2011).

Spatial scales Spatial scales range from local to regional and global, and concern the geographic (spatial) extent of environmental and ecological phenomena, as well as organizational and industrial activities. Different levels on this scale and their interactions have been extensively studied in fields such as ecology (for instance, to understand ecosystems as well as their processes and changes at different levels). However, neither the geographic extent of organizational activities nor the concept of 'place' has received much attention in business research and practice. Business decisions on issues to do with geography or spatial scales are mainly related to economic considerations for the location of organizational activities (that is, which is the best location for production) and the expansion and 'scaling-up' of organizational activities (that is, organizational growth). Such considerations include the expansion into lucrative markets, increasing overall market size, responding to overseas competition, achieving cost-savings due to economies of scale, or gaining overseas cost advantages due to lower wages, resources access, or desirable infrastructure (Brouwer et al., 2004; Linnenluecke and Griffiths, 2011; Lloyd and Dicken, 1972).

The issues that have typically not been considered concern the impacts of the geographic scale and the scope of organizational activities on communities and the natural environment. Some organizations have been criticized for exploiting resources on a large scale to further their economic goals, paying little attention to the extent of resource use and resulting impacts on ecosystems, society and local communities. Such criticisms have been raised in particular about multinational corporations (MNCs), and especially by those opposed to globalization. Their concerns are that MNCs are stateless or rootless entities that exploit local 
places for the sole goal of maximizing shareholder value (Shrivastava and Kennelly, 2013). While mobility, global reach and presence in multiple locations have been theorized as essential elements of the competitive advantages of MNCs, these attributes also enable MNCs to tap into a variety of local (and, in particular, natural) resources and significantly scale-up not only their outputs, but also their overall environmental and carbon footprint (Patenaude, 2011; Shrivastava and Kennelly, 2013). Overall, the issue of scale within the business and management field has mostly been addressed in the context of scaling-up economic activities (that is, growth) and 'economies of scale' (that is, optimization of production to improve economic outcomes) (Gibson et al., 2000).

Temporal scales Temporal scales consist of different 'time frames' and related durations, rates or frequencies. This book covers issues at different temporal scales, covering climate dynamics and change, policy developments, as well as organizational responses. Climate dynamics, for instance, are characterized by long durations and slower changes over decades to centuries, and have been excluded from many organizational decision-making frameworks and analyses altogether, especially those used in business decision-making (Egri and Pinfield, 1996; Shrivastava, 1994). However, even though climate dynamics take place over longer periods of time, they can manifest themselves in changes in the frequency and intensity of relatively short-lived phenomena such as weather extremes. Many institutional structures as well as governance structures or ideologies (worldviews) associated with current dominant economic paradigms are also characterized by 'longer' timeframes (Cash et al., 2006). Such slower-moving variables in the 'organizational environment' are consequently regarded as largely exogenous to the organization as they leave limited opportunities for individual organizations to influence them over shorter periods of time (Gibson et al., 2000). Timeframes most relevant for organizational decision-makers are short-term decisionmaking and goal-setting cycles at a strategic level (3-5 years). Operational targets can be even shorter and relate to daily, weekly, monthly or yearly outcomes.

Cross-scale and cross-level interactions The real implications for organizational and industry responses to climate change arise not just from understanding the different scales and levels, but in particular from cross-scale and cross-level interactions and resulting challenges (Cash et al., 2006). This is important for understanding how global systematic changes and phenomena are linked to and regulated by a complex mix of more localized organizational and industrial processes (for example, 
business action on climate change as designed through strategies and carried out through different projects or tasks) and vice versa.

1. Failure to recognize interactions between levels and scales Cross-level and cross-scale interactions can be extremely difficult to understand. Examples include national policies that have unintended consequences on a local level or do not bring about desired changes (for instance, policies that constrain local action or innovation). Other examples are large-scale problems that arise due to the aggregate activities of individual actors (such as the rising concentration of GHGs due to emissions from a large number of distributed actors) or due to a focus on short-term outcomes (for example, profit optimization instead of long-term planning and sustainable solutions). As evident through the impacts brought about by the aggregate levels of industrial activities, local actions can give rise to significant levels of global change. In turn, however, industries and organizations will be impacted by local manifestations of these global changes.

2. Mismatches between ecological systems and human (individual, organizational or industry) actions Many environmental problems are brought about by a mismatch between human actions (human scales) and ecological timeframes (ecological scales). Such mismatches can be brought about by the scale of resource use, where the aggregate level of use of a resource exceeds its local replenishment rate, or where short-term actions (for example, economic growth, resources consumption and electoral cycles) contradict long-term planning requirements. For instance, business and policy plans are often made in rather short-term decisionmaking cycles (3-5 years) that do not allow for long-term decisionmaking and adaptations. Furthermore, there is ample evidence that human environmental management attempts do often not match the scale of the problem (for example, transboundary environmental problems or migratory fisheries). Resulting challenges are matching the scale of knowledge on environmental problems and the scale at which decisions are made and action taken (Kates et al., 2001). This includes, for instance, translating scientific knowledge on global climate change processes into information that has relevance to local decision-makers, and using local, tacit or indigenous knowledge in national or international decisions.

3. Difficulties to understand pluralities among actors, even at the same level Last, there is often the incorrect presumption that there is a single, correct, or best solution that should be applicable 
to all actors at the same level. The simplest example is when a problem is defined as purely 'global' or 'local'. Climate change, for instance, is often framed exclusively as a global issue, which suggests that there needs to be a 'global' solution applicable on an international level. The impetus to frame issues at a single level comes from the need to both simplify and control. Governments, for example, often frame issues so that they can be managed within their jurisdictions. However, from an organizational perspective, finding a global solution is not seen as being of particular relevance. What matters are practical solutions that translate into competitiveness and innovation.

In the next chapter, we move from this preliminary analysis of the history of organizational and industry responses to the global environment to outlining the range of the threats posed by unabated climate change. 